McKenzie, Pamela J.

The University of Western Ontario, London, Ontario, Canada

\title{
"If you try to close them I will stab you in the eye with a fork": interpretative repertoires in public library value statements (Paper)
}

\begin{abstract}
Résumé:
In July 2018, an online post advocating the replacement of libraries with Amazon outlets produced an outpouring of responses that articulated and debated the value of the public library. These value statements represent multiple, intertwined, and sometimes contradictory perspectives expressed in interpretative repertoires. These repertoires cluster around statements of value to the individual and value to society at large and include an association between libraries and the physical print book.
\end{abstract}

\section{Introduction}

On July 21, 2018, Forbes published an opinion piece by contributor and Long Island University economics professor Panos Mourdoukoutas (Mourdoukoutas 2018.07.21), which argued for the replacement of local libraries with Amazon outlets. Between July 21 and 28, the article and its responses received coverage in local, national and international news outlets (e.g., The Guardian, the Halifax Chronicle-Herald) and through multiple content aggregators (e.g., Quartz).

Comments appeared on Twitter, Facebook, blogs, and forums such as Reddit. On July 23, after more than 200000 views (Ha 2018.07.23) and a robust Twitter critique of the lack of evidence in the article, a revised edition appeared on the Forbes website (Mourdoukoutas 2018.07.23). Shortly thereafter, Forbes removed the article altogether and posted a statement distancing themselves from the author's views. By July 26, the original url produced a 404 error and the original and revised Forbes pieces were only available in archived versions.

Over the course of the week following the publication of this challenge from the outside world, the Internet conversation shifted from "Behold this disastrously bad Op-Ed calling for Amazon to replace libraries" (McKay 2018 [July 21]) to "Forbes pulls anti-library article after social media goes apesh*t" (Rowles 2018 [July 24]. Although much of the conversation criticized Mourdoukoutas' scholarship or questioned his motivations, participants in this conversation collectively produced a very large number of spontaneous and vigorous articulations of value statements, both positive and negative, related to public libraries. Responses came from library and book trade insiders, but also from library users, former users, and non-users.

In this paper, I present an initial analysis of competing and complementary discursive building blocks - interpretative repertoires -- evident in this unique and impassioned discussion and debate of public library value statements. 


\section{Literature review and theoretical framework}

Public libraries in the English-speaking world have long espoused a set of high-level values (e.g., Gorman 2015, Maxwell 2006) and associated purposes that are generally agreed upon across institutions (e.g. London Public Library 2014), professional organizations (e.g., Book and Periodical Council (Fitch and Warner [1997?]), Canadian Federation of Library Associations 2017, Federation of Ontario Public Libraries 2018), and funding bodies (e.g., Ontario. Ministry of Tourism, Culture and Sport 2018), and have been demonstrated by researchers (e.g., Dervin and Fraser 1985, Horrigan 2015). However, these values are not entirely congruent; for example, maximizing access compromises the preservation of a physical collection, and vice versa. The goal of transmitting (implicitly high) culture to future generations (Maxwell 2006) conflicts with the values of democratizing collections and opening spaces to a more diverse public and of meeting mainstream public demand (Talja 2001).

Public libraries are under increasing pressure to convey, and therefore think about, their value in economic terms (e.g., Aabø 2009, Federation of Ontario Public Libraries 2017). McKenzie and Stooke (2012) argued that in an environment where public libraries are competing for public attention and for public and private funding, it is crucial to pay attention to the goals and purposes emphasized by a variety of participants and stakeholders. They found that library staff and users sometimes emphasized different values and goals, and therefore saw different purposes for public library spaces, collections, programs, and services. In some cases the varying purposes were so different that they created tension or conflict, or led to social exclusion. This paper responds to McKenzie and Stooke (2012) and builds on prior studies of the values of public libraries (e.g., Horrigan 2015) by taking a social constructionist approach to analyzing the discursive building blocks (interpretative repertoires) underlying public library values statements (Talja 2001).

\section{Methodology and methods}

A constructionist perspective assumes that an individual may develop a variety of different statements about libraries. Although they may be mutually inconsistent, these statements may coexist within a single account. Regularity within the accounts of a single individual is therefore less interesting than the regularity that exists in the elements used by different writers to describe the values of public libraries. Wetherell and Potter (1988 p.171) argue that a range of accounts of the same phenomenon will contain the same "relatively internally consistent, bounded language units which we have called ... interpretative repertoires." For example, Talja (2001) identified three interpretative repertoires at play in interviews with music library users.

This paper reports on the initial analysis of interpretative repertoires in a sample of responses to the 21 July Forbes post. The sample consists of posts that a) were freely available on the open Web, b) were published or posted between July 21 and 28 2018, and c) specifically mentioned the Forbes post. I conducted two Google searches, on July 26 and July 28 2018. I searched two different phrases, because not all sources mentioned the author: "panos mourdoukoutas" forbes public libraries; "forbes article" OR "article in forbes" libraries Amazon. A broader search 
(forbes libraries amazon) resulted in a massive number of false hits. I also monitored Facebook posts from Librarianship.ca, which curates news stories of all types about libraries worldwide, and followed links that appeared on my personal Facebook feed between July 21 and 282018.

Between July 26 and July 31, I checked every url, removing false hits (e.g., on an older Forbes story about Amazon e-readers replacing public libraries) and duplicates. From this process I developed a sample of 140 individual English-language sources, which I saved locally. Sources ranged from short (e.g., comments on articles and public fora), to long-form journalism, blog posts, and forum discussions (e.g., 96 comments on a Breitbart News post). Rather than selecting all relevant Twitter hashtags and retweets, I saved and analyzed the direct responses to Mourdoukoutas' two tweets, and comments on those responses. Authors included library and book trade insiders; library users and non-users; news reporters; business, technology, education, and parenting bloggers or columnists, anonymous contributors to discussion fora (including literature, libraries, regional, and unrelated hobby topics); and members of the general public commenting on news articles or tweeting responses.

Identification and analysis of interpretative repertoires occurred over multiple steps using $\mathrm{N}$ Vivo. The first step was to identify relevant instances within the sources, excluding, for example, discussion of Forbes' editorial policies or the author's credentials. I identified both explicit and tacit statements, for example an implicit description of what the library does or does not do through a description of what Amazon does or does not do, or a mention of public libraries within a discussion of the value of other tax-supported services like public education. Subsequent analytic iterations identified and analyzed interpretative repertoires, which required focusing on variations in the ways discourse is constructed, both within and across accounts (Wetherell and Potter, 1988 p.171).

\section{Findings}

A discourse analysis allows us to see public library value statements as flexibly and dynamically composed of foundational interpretative repertoires. The statements do address accepted tenets of library value, including that the library's purpose is/should be (or, is not/should not be):

- a place for education;

- a place for literacy;

- a quiet place conducive to serious/scholarly work;

- a place for children;

- a busy places that is in high demand;

- a site of social inclusion: a place for those who have no other place;

- a repository of culture and knowledge, particularly that contained in print books;

- a defender of democracy and intellectual freedom;

- staffed by educated, competent professionals

- worthy of state financial support. 
However, writers used and flexibly combined these repertoires to tell particular kinds of stories. These stories had several separate but interrelated loci. One is on the individual, and addressed how the library is (or is not) personally important or valuable to the writer. A second addressed the library's importance and value to some broader community.

I pretty much never use my town's library but there is no way I would condone de-funding it, even if it meant lowering my tax bill, for the same reason that I routinely vote in favor of improvements/upgrades to the local schools even though I don't have kids in the school system.......it benefits the entire community when its students have access to the structure, discipline and education a superior school system provides and its residents have access to a place that can provide them with a safe place to experience cultural, social and educational enlightenment. Also, if you try to close them, I will stab you in the eye with a fork.

The example below draws on both personal value ("I am happy to pay my share of taxes") and societal value ("part of American Culture"), and addresses the repertoires of education and implicitly, high culture ("improvements of all minds"):

It is a part of American Culture to provide a system of public libraries for the improvement of all minds. I am happy to pay my share of taxes, as libraries are an essential part of the fabric of our society.

A third emphasizes (either positively or negatively) the relationship between the library and print books, with many statements contending that the library's main and proper role should be the custodianship and sharing of paper books. The following example draws on the literacy, education and children repertoires to emphasize the purpose of the library as a repository of paper books:

About the only thing I'd like to see in libraries is $100 \%$ emphasis on *books*--and a very minor emphasis on computer terminals, if they have to have any at all. I am $100 \%$ pro-tech-worked in it for 35 years--but I think libraries are places of *books. * Get kids hooked on reading and they'll never stop. There is nothing like a book in hand--using a Kindle is no substitute, imo.

Writers frequently associated books and therefore books with the past, and digital resources with the present or future. These associations were both nostalgic, emphasizing the physicality of the reading experience and the library as a valuable place from one's past:

I worked in a library for a summer in High School and I miss the smell of the books so much!

and disparaging, representing the library as not sufficiently future-facing and making the case for more investment in digital resources, not just books.

Well, hardcopies nowadays are meant mostly for middle-aged people or retirees. 


\section{Discussion}

Analyzing the interpretative repertoires underlying these spontaneous public statements on the value of the public library allows us to glimpse the different and often conflicting purposes commenters associate with them. As Talja (2001) found, Finnish music library users variously privileged the library and the music collection as 1) a site for education and a respository of "high" or mainstream music; 2) a place of social inclusion and a collection that reflects a diversity of musical forms and origins; 3 ) a democratic place and a collection that properly follows local demand. Making these interpretative repertoires visible can assist public libraries and LIS scholars in understanding, responding to, and, where necessary, challenging the values and purposes espoused in the world outside of the library community.

\section{Reference List}

Aabø, Svanhild. 2009. "Libraries and return on investment (ROI): a meta-analysis." New Library World 110 (7/8):311-324. doi: 10.1108/03074800910975142.

Canadian Federation of Library Associations. 2017. CFLA/FCAB Endorses ALA Defence of Library Core Values, Feb 3, 2017. http://cfla-fcab.ca/en/advocacy/cflafcab-endorses-aladefence-of-library-core-values/

Federation of Ontario Public Libraries. 2017. Helpful list of public library value studies in Ontario http://fopl.ca/news/helpful-list-of-public-library-value-studies-in-ontario/

Federation of Ontario Public Libraries. 2018. Five ways you can turn your library into a community hub. http://fopl.ca/news/5-ways-you-can-use-partnerships-to-transform-yourlibrary-into-a-community-hub/

Dervin, Brenda and Benson Fraser. 1985. How libraries help. Stockton, CA: University of the Pacific, Department of Communication.

Fitch, Leslie and Jody Warner. [1997?]. Dividends: the value of public libraries in Canada. Library Action Committee of the Book and Periodical Council.

Gorman, Michael. 2015. Our enduring values revisited: librarianship in an ever-changing world. Chicago: ALA Editions.

Ha, Thu-Hong. 2018.07.23. Forbes deleted a deeply misinfomed op-ed arguing Amazon should replace libraries. Quartz. https://qz.com/1334123/forbes-deleted-an-op-ed-arguing-thatamazon-should-replace-libraries/

Horrigan, John. 2015. Libraries at the Crossroads. Pew Research Center. Available at: http://www.pewinternet.org/2015/09/15/2015/Libraries-at-crossroads/

London Public Library. 2014. Strategic plan: Library Space is Community Space. http://www.londonpubliclibrary.ca/page/strategic-plan-2014-2017

Maxwell, Nancy Kalikow. 2006. Sacred stacks: the higher purpose of libraries and librarianship. Chicago, IL: American Library Association.

McKay, Tom. 2018.07.21. Behold this disastrously bad op-ed calling for Amazon to replace libraries. Gizmodo. https://gizmodo.com/behold-this-disastrously-bad-op-ed-calling-foramazon-t-1827789820 
McKenzie, Pamela J. and Rosamund K. Stooke 2012. Making a difference: the importance of purposes to early learning programs. Children and Libraries Summer/Fall 2012, 47-52.

Mourdoukoutas, Panos. 2018.07.21. Amazon Should Replace Local Libraries to Save Taxpayers Money. Forbes. [cached version: original removed July 24] https://webcache.googleusercontent.com/search?q=cache:8PgKyKS8rdoJ:https://www.fo rbes.com/sites/panosmourdoukoutas/2018/07/21/amazon-should-replace-local-librariesto-save-taxpayers-money/amp/+\&cd=10\&hl=en\&ct=clnk\&gl=ca\&client=firefox-b

Mourdoukoutas, Panos. 2018.07.23. Amazon Should Replace Local Libraries to Save Taxpayers Money. Forbes. [cached version: original removed July 24] http://archive.is/mPceN

Ontario. Ministry of Tourism, Culture, and Sport. 2018. News Release: Ontario Making the Largest Investment in Public Libraries in a Generation; Province Boosting Access to Technology, Digital Library Resources. May 4, 2018 10:00 A.M. https://news.ontario.ca/mtc/en/2018/05/ontario-making-the-largest-investment-in-publiclibraries-in-a-generation.html)

Rowles, Dustin. 2018.07.24. Forbes pulls anti-library article after social media goes Apesh*t. http://www.pajiba.com/miscellaneous/forbes-pulls-antilibrary-article-after-social-mediagoes-apesht.php

Talja, Sanna. 2001. Music, culture, and the library: an analysis of discourses. Lanham, MD: Scarecrow Press.

Wetherell, Margaret and Jonathan Potter. 1988. Discourse analysis and the identification of interpretive repertoires. C. Antaki (ed), Analysing everyday explanation: a casebook of methods (pp. 168-183). Newbury Park, CA: Sage. 